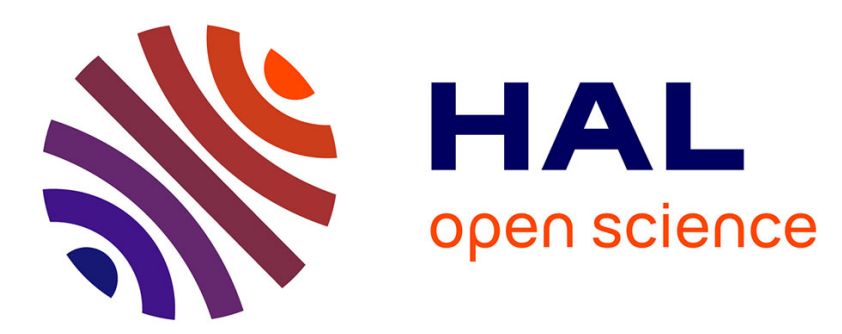

\title{
A multi-objective comparison of dispatching rules in a Drum-Buffer-Rope production control system
}

\author{
Pedro L. Gonzalez-R, Jose M. Framinan, Rafael Ruiz-Usano
}

\section{To cite this version:}

Pedro L. Gonzalez-R, Jose M. Framinan, Rafael Ruiz-Usano. A multi-objective comparison of dispatching rules in a Drum-Buffer-Rope production control system. International Journal of Computer Integrated Manufacturing, 2010, 23 (02), pp.155-167. 10.1080/09511920903440362 . hal-00558524

\section{HAL Id: hal-00558524 \\ https://hal.science/hal-00558524}

Submitted on 22 Jan 2011

HAL is a multi-disciplinary open access archive for the deposit and dissemination of scientific research documents, whether they are published or not. The documents may come from teaching and research institutions in France or abroad, or from public or private research centers.
L'archive ouverte pluridisciplinaire HAL, est destinée au dépôt et à la diffusion de documents scientifiques de niveau recherche, publiés ou non, émanant des établissements d'enseignement et de recherche français ou étrangers, des laboratoires publics ou privés. 


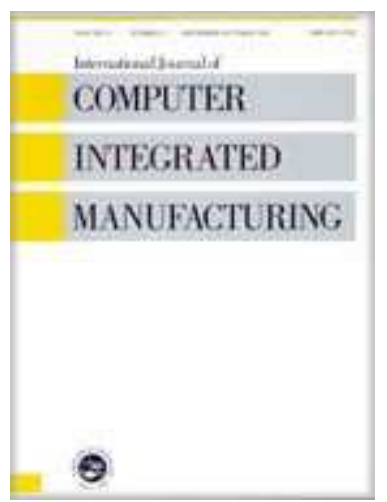

\section{A multi-objective comparison of dispatching rules in a Drum-Buffer-Rope production control system}

\begin{tabular}{|c|c|}
\hline Journal: & International Journal of Computer Integrated Manufacturing \\
\hline Manuscript ID: & TCIM-2009-IJCIM-0039.R1 \\
\hline Manuscript Type: & Original Manuscript \\
\hline $\begin{array}{r}\text { Date Submitted by the } \\
\text { Author: }\end{array}$ & 24-Jul-2009 \\
\hline Complete List of Authors: & $\begin{array}{l}\text { Gonzalez-R, Pedro L.; University of Sevilla, Industrial Management, } \\
\text { School of Engineering } \\
\text { Framinan, Jose M.; University of Sevilla, Industrial Management, } \\
\text { School of Engineering } \\
\text { Ruiz-Usano, Rafael; University of Sevilla, Industrial Management, } \\
\text { School of Engineering }\end{array}$ \\
\hline Keywords: & $\begin{array}{l}\text { PRODUCTION CONTROL, PRODUCTION MANAGEMENT, } \\
\text { OPTIMIZATION }\end{array}$ \\
\hline Keywords (user): & Theory Of Constraints \\
\hline
\end{tabular}

\section{S scholarONE" \\ Manuscript Central}




\title{
A multi-objective comparison of dispatching rules in a Drum-
}

\section{Buffer-Rope production control system}

\author{
Pedro L. Gonzalez-R ${ }^{*} \dagger$, Jose M. Framinan $\uparrow$ and Rafael Ruiz-Usano $\dagger$ \\ $\dagger$ Industrial Management, School of Engineering, University of Seville, Seville, Spain.
}

\begin{abstract}
The advantages of the TOC (Theory of Constraints) philosophy have been extensively documented in the literature since its introduction during the $80 \mathrm{~s}$. At the operational level, TOC is implemented by means of the well-known DBR (Drum-Buffer-Rope) production control system. In a multiproduct manufacturing environment, the performance of DBR is greatly affected by the dispatching rules employed in front of the bottleneck station. Furthermore, it has been proved that no single Dispatching Rule (DR) performs globally better than any others. Therefore, for systems usually influenced by variability conditions, the selection of a robust DR could help practitioners to reach a good system performance. In this paper we propose a methodology to obtain a robust DR (by means of Taguchi signal-to-noise ratio) from a set of previously selected rules according to the performance measures of the system pursued by the practicing managers. We study the performance of different dispatching rules for several conflicting objectives (namely average tardiness, maximum tardiness, and WIP) from a robustness viewpoint and for a range of manufacturing scenarios in a shop floor formed by five stations in line and three different products. Different variability sources, such as processing times, breakdowns and set-ups, are discussed. The results obtained are of special interest for practitioners.
\end{abstract}

Keywords: Production Control systems; Drum-Buffer-Rope; Theory Of Constraints; Taguchi; Multiobjective.

\footnotetext{
* Corresponding author. Email: pedroluis@esi.us.es. Tel: + 34954487219, Fax: +34954487329

Departamento de Organización Industrial y Gestión de Empresas. Escuela Superior de Ingenieros. Avda. de los Descubrimientos, s/n, 41092. Sevilla, SPAIN.
} 


\section{Introduction}

Manufacturing management switched during the 70s from mass production -and Just in Case (JIC)- to Just in Time (JIT). JIT is usually implemented at the shop floor level by means of the well-known Kanban production control system (Monden, 1983), initially developed for Toyota and successfully put into practice in a wide variety of manufacturing environments. After the JIT revolution, the Theory of Constraints (TOC) appeared in the 80s, focusing on identifying and exploiting system's constraints. Similarly to JIT, TOC is implemented at the operational level by means of the so-called DBR (DrumBuffer-Rope) production control system (Goldratt and Fox 1986). Since its introduction, DBR has attracted a great deal of attention both from scientist and practitioners. Among the main contributions of theoretical nature, it is worth to mention Schragenheim and Ronen (1990, 1991), Daniel and Guide (1997), Simons et al. (1999), Kodipasaoglu et al. (2000), Sivassubramanian et al. (2000), Chakravorty (2001), Blackstone (2002), Gilland (2002), Riezebos et al. (2003), or Koh and Bulfin (2004), while the following works focus on practical implementations and applications of DBR: Guide (1996), Russel and Fry (1997), Kempf (1998), or Corbett and Csillag (2001).

In an extensive series of experiments, Duenyas (1994) shows that the most important feature affecting the performance of a production control system is the input control (i.e. when to release a job into the system), and that scheduling decisions (which type of job to be processed) are strongly dependent on input control and on the position of the bottleneck in the system. As in the DBR production control system there exist a strong relationship between the buffer in front of the bottleneck and the input control in the system, scheduling the jobs in front of the bottleneck seems to play an important role in the performance of this system. This aspect was previously stated by Baker (1984) when studying a simplified model, stressing the importance in the interconnection between the input control and the scheduling procedure.

Among the different approaches to schedule jobs in a system, dispatching rules (DRs) are widely used in practise, particularly in these scenarios where manufacturing is affected by different sources of variability, 
as global scheduling seems to be unsuitable in these cases. Indeed, Aytug et al. (2005) and Lawrence and Sewell (1997) remark that for systems with high uncertainty (as in the system under consideration in our work), completely reactive algorithms (i.e. dispatching rules) can be used with relative confidence and question the benefits of global scheduling procedures. In this line, the influence of priority rules on the performance of different production control systems has been studied by several authors (see e.g. Montarezi and Van Wassenhove (1990), Kayton et al. 1997, Lixing et al. (2000), or Lee et al. (2009).

The previous works compare the performance of a set of dispatching rules for a specific manufacturing scenario according to a single criterion. However, when selecting a suitable dispatching rule in practice, one should balance several (usually conflicting) criteria. This is a key issue, as previous simulation studies show that no single dispatching rule outperforms the other for every objective (see e.g. Montazeri and Van Wassenhove, 1990, or Pierreval and Mebarki, 1997). Focussing specifically on the DBR system, some contradictory results are found. Chakravorty (2001) stressed in his conclusions that more research regarding the influence of the DRs in DBR systems should prove to be useful for both researchers and practicing managers. The author only studied the SPT and FCFS rule, obtaining better results for the SPT rule. These results seem to be contrary to those obtained by Schragenheim and Ronen (1990) and Umble and Srikanth (1990) which obtained a poor performance of SPT. Furthermore, Kayton et al. (1996) and Kayton et al. (1997) studied the FCFS and the CR rule, showing that the best performance was obtained by the CR rule. Daniel and Guide (1997) focused their work in the influence of the DRs for non-bottleneck buffers, obtaining the better results for the FCFS and EDD rules. Other results have been obtained for different shop floor conditions, such as assembly and shared machines (Kayton et al. 1997), reprocessing (Daniel and Guide 1997), or job shop environments (Chakravorty 2001).

It is clear that DR performance is highly influenced by the production scenario, but it is also obvious that changes in the manufacturing environment due to the inherent variability of the shop floor can influence this performance as well. Therefore, it is not useful to select a dispatching rule if its performance quickly 
deteriorates when the initial conditions change due to breakdowns, unbalancing, set-ups, etc. In order to correctly select a DR, two possible approaches can be distinguished: (1) introducing a more or less sophisticated mechanism that dynamically switches in real-time the DR and select the best one, according to the environmental conditions, or (2) selecting a robust DR, i.e. using a DR which can stand different environmental changes. The former approach is known as Switch From Standard Rules (SFSR) heuristics (see Ramesh, 1990 for a survey of dynamic DRs). Some recent works used a Neuronal Network for a dynamic selection of DRs (see e.g Mouelhi-Chibani and Pierreval, 2009). Lee et al. (2009) based their approach on a model based on the extended object oriented Petri nets (EOPNs). To our best knowledge, the second approach (selecting a robust DR) is novel and constitutes the main contribution of this paper. Although the main advantage of the SFSR approach is its efficiency, these methods are too much sophisticated and require a real-time monitor in order to be implemented in practise. This aspect goes against the TOC philosophy and DBR, which advocate easy methods to be used in practise. Therefore, our work focuses on the second approach, analysing the influence of dispatching rules in the performance of a DBR system and trying to determine the most robust one under certain variability conditions.

In order to do that, we first conduct an experimental design based on several sources of variability taken from real manufacturing environments, i.e.: stochastically time process, unbalanced lines, machine breakdowns or set-up times. By using simulation, three locally performance measures widely used in manufacturing practice, i.e.: average tardiness, maximum tardiness, and average work in process (see e.g. Blackstone et al., 1982, Baker, 1984, or Lalas et al., 2006) are calculated. Finally, the global performance of each dispatching rule for different scenarios is computed according to its robustness, employing Taguchi's robustness concepts, which are widely used in selection problems (see Taguchi, 1996 and Moeeni et al., 1997).

The remainder of this paper is organised as follows: In section 2, the DBR production control system is described. Section 3 is devoted to describe the conditions of the experiments, such as flow line parameters, 
simulation parameters, selected DRs, local and global performance measures, and scenarios. Section 4 shows the main results of the experiments, while the last section is devoted to obtain conclusions and remark future research work.

\section{Drum-Buffer-Rope production control system}

The DBR production control system is derived from the Theory of Constraints (TOC) introduced by Goldratt during the 80s (see e.g. Goldratt and Cox, 1984). It is known that a great number of companies have implemented TOC successfully (Mabin and Balderstone, 2000), while there is a certain interest in the mechanism among practicing managers (Erenguc et al. 1997). This methodology was a result of previous studies and the development of the production planning software known as OPT (Optimized Production Technology). TOC is based on the premise that the rate of goal achievement is limited by at least one constraining process. Only by increasing flow through the constraint can overall throughput be increased (see e.g. Goldratt and Cox, 1984). From the 90s up to now, TOC concepts were opened to the management field, being this extension known as Thinking Process, TP (see e.g. Goldratt, 1990, or Ye and Han, 2008).

The Five Focusing Steps of TOC are (Goldratt, 1990):

1. Identify the system constraint(s)

2. Exploit the constraint(s)

3. Subordinate all other decisions to step 2

4. Elevate the constraint

5. If constraint has moved, return to step 1. Don't let inertia become the constraint.

At the shop floor level, TOC is usually implemented by means of the DBR production control system. DBR is composed by three elements: Drum, Buffer and Rope. Goldratt and Cox (1984) show that the lower capacity station governs the throughput rate of the entire manufacturing line. This station is known as the 'drum', or CCR (Capacity Constraint Resource). The input control mechanism is the 'rope', and it is 
based on the utilization of the bottleneck. Finally, the 'buffer' represents the time period for an early arrival of jobs to the bottleneck from the entrance in the system. A detailed description DBR production control system can be found in Goldratt and Cox (1984), Goldratt and Fox (1986), Schragenheim and Ronen (1990) or Spencer and Cox (1995).

Two alternative input control mechanisms could be employed in the DBR system (Goldratt, 1990): In the first case ('time buffer'), an input rate is established, while the work in process (WIP) upstream the CCR fluctuates according to the stochastic behaviour of the system. Note that this rate should be periodically adjusted, otherwise it can result in infinite WIP. In the second case ('WIP buffer'), WIP upstream the CCR is established, while input rate fluctuates. Most authors (see e.g. Lambrecht and Segaert, 1990, Ramsay et al., 1990,or Gilland, 2002) adopt the latter mechanism in their works, thus describing a DBR control system which limits the maximum WIP upstream the bottleneck by using cards to authorise the entrance of jobs in the system. This mechanism is similar to the Conwip production control system (Spearman et al., 1990), although the latter limits the WIP in the whole system. In Figure 1 is shown a typical implementation of the WIP-buffer DBR system for a line formed by five stations in tandem, with a bottleneck station in the central position.

[Insert Figure 1 about here]

Figure 1. WIP-buffer DBR implementation

In Figure 1, the flow of material is shown in continuous line, while the flow of cards is represented in doted lines. The input control procedure is as follows: a job can enter the system if there is at least one card in the control panel. If so, the card is attached to the job until the job finishes it operation in the CCR. Once the job exits the CCR, the card is released and sent back to the control panel. Clearly, the maximum WIP is bounded by the number of cards in the system, being this number the main parameter governing its performance. 
[Insert Figure 2 about here]

Figure 2. WIP-buffer DBR implementation for three type of products

As discussed before, the WIP upstream the CCR is limited by employing cards. As we consider a multiproduct environment, individual cards counts can be set for each job (M-Closed input rule), or by establishing a single card count for all jobs (S-Closed input rule). Since Duenyas (1994) and Framinan et al. (2000) show that M-Closed is more effective than S-Closed, different card counts are employed for each product type (see Figure 2). In the system under consideration, the type of product that is allowed to enter the system is determined by the type of cards available in the control panel, and consequently there is no need to establish an input sequence for the jobs. Although in the long term time-buffer and WIP-buffer approaches are intertwined with Little's Law, in the sequel we adopt the latter, as it is the most often described and employed in practise.

\section{Research Methodology}

The research methodology is presented in five sections. First, we describe the model and hypotheses considered in the subsequent experiments. Next the selected DRs are introduced. Local performance measures for the system working under a certain DR are explained and the global performance measure to be computed for each DR over all scenarios is explained through the robustness concept, as well as the way to compute it. Finally, the scenarios to be conducted are presented. The proposed methodology can be summarized in the following steps:

1. System description. As mentioned earlier, DRs are very sensitive to the type on system (flow-shop, job-shop, assembly, etc,...). Detail all sources of variability in the system: set-up, breakdowns, reentrant flows, etc,... They will be considered as noise factors in order to compute the robustness.

2. Selection of local performance measures. Take into account the performance measures for the environment as well as the management point of view: average tardiness, WIP, service level,... These local criteria will be used also as noise factors, in order to obtain robust DRs under different performance measures. 
3. DRs selection, according to the local performance measures can be selected some DRs than shown in literature to perform well literature. We could also based on previous experiences.

4. Definition of the Scenarios, taking into account every source of variability and every performance measure. The system is modelled and a simulation design of experiments is conducted.

5. Definition of Global performance measures. Compute the robustness of the different DRs in order to obtain the most robust DR or a ranking of rules.

\subsection{System description}

Our study focuses on a flow-line formed by five stations in tandem using the DBR system shown in Figure 2. The problem under consideration is based on a real-life problem encountered at a gear-box factory, where three types of parts have to be produced in the same line, sharing the same machines, and later assembled in the gear box. In this line, the machines had breakdowns as well as set-up times were necessary in order to change the tools. These variables, based on a real-life problem are introduced in our model. We consider infinite raw material availability in the first station, i.e. jobs may enter the system if there are kanbans available for this job type in the control panel. The work in process (WIP) start counting once the job is entered the system. This is a common assumption in this type of simulation studies (see e.g. Bonvik et al., 1997). Each station is composed of an input buffer and a machine. We consider three different types of products (I, II and III), sharing the same bottleneck under a make-to-order environment. The bottleneck is located in the central station of the line. Every buffer operates under a FCFS (First Come First Served) dispatching rule as suggested by Umble and Srikanth (1990), with the exception of the CCR buffer, which could follow different dispatching rules. For every type of job is defined a target level of jobs produced in the simulation period, defined as the $20 \%, 30 \%$ and $50 \%$ for jobs type I, II and III respectively.

The system variability was modelled through processing time variation, CCR downtime and set-up times inclusion, following the recommendations of Law and Kelton (1991) and trying to reproduce a hypothetical situation of a real environments. Processing times were generated from a log-normal 
distribution with means $15.0,10.0$ and 5.0 and a coefficient of variation (cv) equals to 0.2 . The system performance is studied according two different levels of the CCR processing times, increased a $15 \%$ or $30 \%$ regarding to the processing times of the non-bottleneck stations. Additionally, we consider system downtime and set-up in the CCR for certain scenarios. These are only considered for the bottleneck station, as it has been shown that fluctuations in the bottleneck station influence the performance of the system more than similar fluctuations in other stations (see e.g. Fry et al., 1992). Breakdowns were generated by exponential distributions with mean of 100 for the MTBF (Mean Time Between Failures) and 25 for the MTTR (Mean Time To Repair). This constitutes a system down time of $20 \%$, or an availability of $M T B F /(M T B F+M T T R)$ equals to 0.8 . The CCR utilization rate was established to $95 \%$ for those scenarios without downtimes and $80 \%$ for those with breakdowns. For those scenarios with set-up times, a set-up time generated by a log-normal with mean a set-up time of 100 and a $c v$ of 0.2 , each time a new type of job is processed on the bottleneck. Finally, in order to set the due-dates of each job, we consider that at least a $10 \%$ of the jobs are considered as urgent, similar to Kayton et al. (1997). Thus for jobs released at time $t$, the due dates $D D_{i}$ of job $i$ are given by $D D_{i}=t+K \cdot \sum_{j} t_{i j}$, where:

$t_{i j}$ is the mean processing time of job $i$ in machine $j$ at time $t$.

$K$ is the allowance factor generated by a uniform distribution $U(1.5,2)$ for normal jobs, and $U(0.5,1.5)$ for urgent jobs.

By using this method we can obtain a certain guarantee about the independence of the $D D_{i}$, avoiding the correlation of due dates with certain rules. Additionally, has been taken into account some constrains regarding the throughput for every product type. Therefore, it was established that the percentage of finished jobs in the simulation horizon for every type of job should be greater than a target value less an allowance factor of $5 \%$. Thus, the target throughput mix is $20 \%, 30 \%$ and $50 \%$ for products I, II and III respectively. 


\subsection{Local performance measures}

The system's performance was measured locally for every scenario using three different criteria. Two criteria were used to asses the system's ability to deliver in time. One criterion was the mean tadiness. Previous research has shown that mean tardiness, $\bar{T}$, measured as the average amount of positives times by wich the completion time of a job exceeds its due date, are good measures to evalute the performance of scheduling systems (Blackstone et al., 1982). The other criterion was the maximum tardiness, $T_{\max }$, (see e.g. Lalas et al., 2006). The last studied criterion was the average work in process, $\overline{W I P}$, i.e. the average amount of jobs in the line (see e.g. Chang et al., 1996). Usually, the mean flow time is measured, however, Baker (1984) has shown that there is a direct relationship between $\overline{W I P}$ and mean flow time.

\subsection{Selected Dispatching rules}

The selection of a set of candidate DRs is not an easy task, because of the contradictory results reported in literature and the vast research regarding the topic. There are several reviews: see e.g. Blackstone et al. (1982), Baker (1984), Montarezi and Van Wassenhove (1990), Ramesh (1990), Engell and Moser (1992), or Panwalkar and Iskander (1997) who classified 113 DRs. However, a universally accepted result of these studies is that no DR performs globally better than any others (Pierreval and Mebarki, 1997). Therefore, in our study it seems reasonable to use some DRs according to the environment and performance measures selected in the previous steps. According to that we have selected the following DRs: SPT, SRPT, LPT, SI, EDD, LS, CR, FCFS and SRO. DRs based on times (such SPT or SRPT) performs well on minimising the mean flowtime (or minimising the WIP), but obtain poor results for other criteria such minimising the maximum tardiness. The LPT is introduced as a benchmark for a comparison against other time-based rules. Rules based on due dates could work well in order to produce a delivery of jobs in time. This is the reason to include EDD, LS, CR, and the SI rules (in the appendix, the reasons to consider the SI rule as a due date based DR are explained). The NSUT rule could be interesting for this environment under set-up events. The FCFS rule is also included because it works well for a wide variety of conditions. Finally, the 
random selection rule, SRO, it is included in the study as a benchmark for all the DRs. Details of these DRs are included in the appendix section.

Note that the selection of these rules has been done taking into account also those focused on their influence in the performance of a DBR system (see e.g. Schragenheim and Ronen, 1990; Daniel and Guide, 1997; Chakravorty 2001). Finally, we also take into account the work of Fry et al. (1992), who discuss the influence of set-up times in the bottleneck.

\subsection{Scenarios}

In our analysis we consider two different scenarios depending on the absence or existence of set-up times (scenarios A and B, respectively). For each scenario, we consider two different situations depending on the values of two parameters: $\Delta t_{b}$, the increment of processing time in the bottleneck station (which can take the values $+15 \%$ or $+30 \%$ compared to those in other stations, as described in a previous section), and the existence or not of machine breakdowns (typed as YES or NOT), with the MTBF and MTTR values described in section 3.1. The combinations of the mentioned two variables -that is, a $2^{2}$ or full factorial design- yields four different experiments for each scenario to test each dispatching rule. The full study implies a total amount of 228 experiments. For each mean value, a $99 \%$ confidence interval has been taken into account. For each scenario has been obtained the best set of kanbans that reach the best performance for the studied scenario using the ARENA 12.0 simulation software and the OptQuest optimization tool. Regarding the simulation horizon, some pilot experiments were conducted to appropriately set a single long run of $35010^{3}$ time units and a warm-up of $10^{3}$ in order to obtain statistically reliable results.

\subsection{Global performance measure: Robustness}

As mentioned earlier, there is a vast body of research dealing with the DR, and a few works studying their influence in the DBR system under different criteria. However, to our best knowledge, there is not study trying to determine the DR under different variable conditions and taken into account all different criteria globally. Regarding to this concern, the robustness concept may play an important role in order to assess 
the practitioners for a DR - or a ranking of DRs - which may be applicable to some real life scenarios. The Taguchi's robustness concepts were traditionally used as tools to select among different products, process or services (see e.g. Moeeni et al., 1997; Taguchi and $\mathrm{Wu}, 1980$; Taguchi, 1986). Although Taguchi methods are not free of criticism, they have been successfully applied on a great variety of industrial environments. Taguchi methods are based on the concept of off-line quality, trying to identify the products, process or services which are robust in the sense that are less variable under changes in the environmental conditions, employing a signal-to-noise ratio to select the most robust product/process (see Taguchi and Wu, 1980; Taguchi, 1986).

Therefore, one could address the selection among the different dispatching rules, working under some variability conditions, as a Taguchi Robustness problem. To do so, the relative utilization of the bottleneck by using different increase $\left(\Delta t_{b}\right)$ of processing time at bottleneck station, and breakdowns can be considered as environmental noise factors. Furthermore, the different performance measures are also computed as noise factors, because the global performance over all responses is also a robustness aspect of interest. The distance, $d$, measured as the percentage deviation of the obtained performance of a certain DR respect to the best result can be considered a quality characteristic to be computed. Hence, the main idea is to select the dispatching rule reaching the smallest distance to the efficient solution for every combination of environmental noise factors. This can be done by means of the following expression (Taguchi, 1986):

$$
\eta=-10 \log \left(\frac{1}{n} \sum_{i=1}^{n} d_{i}^{2}\right)
$$

where:

$\eta$ is the signal-to-noise ratio (in decibels)

$n$ is the number of experiments (12 in this case)

$d_{i}$ is the response for a certain experiment 
Signal-to-noise ratio is computed for different noise factors. Under Taguchi's point of view, one system is better if its signal-to-noise ratio is higher. Finally, note that the expression (1) is advised to be employed in quality responses under 'smaller the better criterion', which is the case in our study as the response is the $d_{i}$ distance. In our case (minimization problem) the signal-to-noise ratio is a simple transformation of the squared difference across different scenarios. Nevertheless, for different optimisation criteria, alternative expressions should be employed (see e.g. Taguchi, 1986).

\section{Results}

Mean values for $d$ on every local performance criterion are shown in order to obtain an idea of the distance from a particular DR to the DR which better performs. Values close to zero indicate that the system performs near to the best obtained DRs. Finally, we compute the signal-to-noise ratio, which takes into account the mean values and variance effects. The so-obtained results are presented for the different scenarios.

\subsection{Scenario A (set-up times not included)}

In this scenario, the NSUT rule is omitted in the comparisons, as it is only applicable in scenarios with setup times. Tables 1 to 3 show the results for the distance, $d$, of the best solution found for each DR respect to the best. The distance has been divided in zones of preference from $z^{(1)}$, were results are promising to $z^{(4)}$, containing DR far to be the best. Each table contains the results for a different local performance measure.

For the criterion of minimising the average tardiness, it was expected that those DR based on due dates may obtain a better result than other rules. Thus, rules EDD, SI and CR are always in the best interval, $z^{(1)}$, respect to the best result found. However, the LS rule, also based on due dates, does not reach competitive results reaching 3 results in the zone $z^{(2)}$. This performance may be produced by the influence by the variability in cycle times, which are used to compute the priority. CR obtains better results in the 
more balanced scenarios, $\Delta t_{b}=15 \%$. FCFS obtains moderate results, since $11.9 \leq d \leq 26.2$. Regarding to the time based rules, it is important to note that SPRT always obtains better results than SPT. Furthermore, SPT yields the worst results in balanced scenarios $\left(\Delta t_{b}=15 \%\right)$, even when compared with the random selection rule SRO. LPT rule is included in $z^{(1)}$ for 3 of the 4 experiments, reaching better results than other time based rules. As a summary, the best results are reached for this criterion by the SI, EDD, and CR rules.

\begin{tabular}{|c|c|c|c|c|c|c|c|}
\hline \multirow{2}{*}{$\begin{array}{c}\text { Breakdowns } \\
\Delta t_{b}\end{array}$} & \multicolumn{3}{|c|}{ NO } & \multicolumn{4}{|c|}{ YES } \\
\hline & $15 \%$ & \multicolumn{2}{|c|}{$30 \%$} & \multicolumn{2}{|c|}{$15 \%$} & \multicolumn{2}{|c|}{$30 \%$} \\
\hline \multirow{6}{*}{$z^{(1)}: 0 \leq d<25$} & EDD 0.0 & SI & 0.0 & $\mathrm{SI}$ & 0.0 & & 0.0 \\
\hline & 0.3 & EDD & 1.1 & EDD & 0.8 & EDD & 1.0 \\
\hline & CR & CR & 6.6 & CR & 4.5 & FCFS & 13.3 \\
\hline & LPT & SPT & 14.9 & LPT & 20.6 & CR & 15.4 \\
\hline & FCFS 11.9 & FCFS & 20.5 & & & LPT & 18.7 \\
\hline & & SRPT & 20.7 & & & SRPT & 22.2 \\
\hline \multirow{3}{*}{$z^{(2)}: 25<d \leq 50$} & 47.1 & LPT & 27.9 & FCFS & 26.2 & SPT & 30.9 \\
\hline & & LS & 32.0 & SRP & 38.4 & & \\
\hline & & & & LS & 39.7 & & \\
\hline$z^{(3)}: 50<d \leq 75$ & 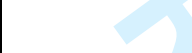 & & & & & & \\
\hline \multirow{3}{*}{$z^{(4)}: 75<d \leq 100$} & SRO & SRO & 100.0 & SRO & 80.5 & SRO & 83.2 \\
\hline & SRPT 78.8 & & & SPT & 100.0 & LS & 100.0 \\
\hline & SPT & & & & & & \\
\hline
\end{tabular}

Table 1. Results for scenario A, $\min \bar{T}$

For the criterion of minimising the maximum tardiness, the results are still clearer that in the previous criterion, in the sense that due date based DR should obtain better results. The SI, EDD, FCFS and LS rules reached the best results always in $z^{(1)}$. Exceptionally, the FCFS rule is the only one that is not based on due dates. It is important to note that the LS rule, which obtained poor results under the criterion of minimizing the average tardiness, seems to work well under maximum tardiness minisation. The CR rule, although due date -based, obtains poor results - close to the SRO rule -, under this criterion. As expected, the time-based rules do not obtain good results, with the exception of the LPT rule, which works in acceptable manner for scenarios under breakdowns. As a summary, the best results are reached for this criterion by the SI, EDD and FCFS and LS rules. 


\begin{tabular}{|c|c|c|c|c|c|c|c|c|}
\hline Breakdowns & \multicolumn{4}{|c|}{ NO } & \multicolumn{4}{|c|}{ YES } \\
\hline$\Delta t_{b}$ & \multicolumn{2}{|c|}{$15 \%$} & \multicolumn{2}{|c|}{$30 \%$} & \multicolumn{2}{|c|}{$15 \%$} & \multicolumn{2}{|c|}{$30 \%$} \\
\hline \multirow{5}{*}{$z^{(1)}: 0 \leq d<25$} & SI & 0.0 & & 0.0 & SI & 0.0 & SI & 0.0 \\
\hline & EDD & 0.3 & EDD & 0.1 & EDD & 0.0 & EDD & 0.1 \\
\hline & FCFS & 0.7 & FCFS & 1.1 & FCFS & 0.1 & FCFS & 0.3 \\
\hline & LS & 6.7 & LS & 4.6 & LS & 1.1 & LS & 1.3 \\
\hline & & & & & LPT & 5.5 & SPT & 10.4 \\
\hline \multirow[t]{2}{*}{$z^{(2)}: 25<d \leq 50$} & & 33.4 & & & SPT & 36.5 & & 27.7 \\
\hline & CR & 43.3 & & & SRPT & 38.4 & SRPT & 34.3 \\
\hline \multirow[t]{2}{*}{$z^{(3)}: 50<d \leq 75$} & SRO & 74.0 & SPT & 64.8 & CR & 53.7 & & \\
\hline & SRP1 & 84.0 & LPT & 70.4 & & & & \\
\hline \multirow{3}{*}{$z^{(4)}: 75<d \leq 100$} & SPT & 100.0 & SRO & 80.6 & \multirow{3}{*}{\multicolumn{2}{|c|}{ SRO 100.0}} & \multirow[t]{3}{*}{ SRO } & \multirow[t]{3}{*}{100.0} \\
\hline & & & SRPT & 84.7 & & & & \\
\hline & & & CR & 100.0 & & & & \\
\hline
\end{tabular}

Table 2. Results for scenario A, $\min T_{\max }$

It should be expected that better results under the criterion of minimising the average work in process should be obtained by the (shortest) time based DR. However, the best performance was reached by the FCFS rule, especially for those scenarios with downtimes. Maybe it was influenced by the strong relationship between the input control and the dispatching rule in the card based DBR systems (see Duenyas, 1994, and Baker, 1984). The FCFS rule produces a stable flow of jobs and cards, obtaining the best way to optimally flow, maintaining low the inventory. The FCFS rule for the Conwip systems, which contains certain similarities with the card based DBR, is also recommended by Hopp and Roof (1998). Furthermore, the SI and EDD rules obtain good results. The implemented SI rule does not allow a job to spend more time than a certain amount of time in the queue (see Appendix sections for the definition of the DRs), being perhaps this aspect the reason for its good performance. Surprisingly, the EDD rule also works fine. In our opinion the behaviour of this rule is also strongly connected to the relation between the input control and the DR. Jobs sorted according to their due dates imply that urgent jobs are pushed to the completion of the process. When jobs finish their processing, a new job of the same type can enter the line. The results seem to indicate an efficient reduction of the WIP is reached with a suitable number of cards. The CR rule obtains a moderate performance, probably for the same reason. The performance for the SPT and SRPT rules are around those of the random selection for the case without downtimes and moderate for 
the case containing breakdowns. As a summary, the best results are reached for this criterion by the SI, EDD, and FCFS rules.

\begin{tabular}{|c|c|c|c|c|c|c|c|c|}
\hline \multirow{2}{*}{$\begin{array}{c}\text { Breakdowns } \\
\Delta t_{b}\end{array}$} & \multicolumn{4}{|c|}{ NO } & \multicolumn{4}{|c|}{ YES } \\
\hline & \multicolumn{2}{|c|}{$15 \%$} & \multicolumn{2}{|c|}{$30 \%$} & \multicolumn{2}{|c|}{$15 \%$} & \multicolumn{2}{|c|}{$30 \%$} \\
\hline \multirow{6}{*}{$z^{(1)}: 0 \leq d<25$} & EDD & 0.0 & SI & 0.0 & FCFS & 0.0 & FCFS & 0.0 \\
\hline & SI & 10.4 & EDD & 6.7 & EDD & 4.9 & SI & 9.0 \\
\hline & FCFS & 10.7 & FCFS & 8.1 & SI & 7.5 & EDD & 9.1 \\
\hline & |LPT & 23.5 & $\mathrm{CR}$ & 14.8 & CR & 7.7 & LPT & 14.8 \\
\hline & & & & & LPT & 13.7 & LS & 20.8 \\
\hline & & & & & & & SRPT & 21.6 \\
\hline \multirow[b]{2}{*}{$z^{(2)}: 25<d \leq 50$} & LS & 25.6 & & & SRPT & 25.6 & CR & 31.5 \\
\hline & $\mathrm{CR}$ & 26.7 & & & SPT & 39.6 & SPT & 48.1 \\
\hline \multirow[t]{2}{*}{$z^{(3)}: 50<d \leq 75$} & SRO & 53.4 & SPT & 61.3 & & & & \\
\hline & SRPT & 63.2 & LS & 72.4 & & & & \\
\hline \multirow[b]{2}{*}{$z^{(4)}: 75<d \leq 100$} & SPT & 100.0 & LPT & 79.1 & SRO & 81.7 & SRO & 100.0 \\
\hline & & & $\begin{array}{l}\text { SRPT } \\
\text { SRO }\end{array}$ & $\begin{array}{r}82.3 \\
100.0\end{array}$ & & 100.0 & & \\
\hline
\end{tabular}

Table 3. Results for scenario A, $\min \overline{\overline{W I P}}$

Regarding the robustness global criteria, results are summarized in Table 4 and in Figure 3. In order to obtain positive robustness values, results (distance $d$ ) are given as a fraction of unity.

\begin{tabular}{|c|c|c|c|c|c|c|c|c|c|c|c|c|}
\hline & Criteria & Breakdows & $\Delta t_{b}$ & SPT & SRPT & LPT & SI & EDD & LS & CR & FCFS & SRO \\
\hline \multirow{12}{*}{ 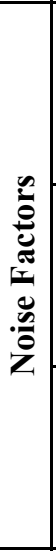 } & \multirow{4}{*}{$\min \bar{T}$} & NO & 15 & 1.000 & 0.788 & 0.056 & 0.003 & 0.000 & 0.471 & 0.004 & 0.119 & 76 \\
\hline & & NO & 50 & 0.149 & 0.207 & 0.279 & 0.000 & 011 & 0.320 & 0.066 & 205 & 000 \\
\hline & & $\bar{Y}$ & 15 & 1.000 & 0.384 & 0.206 & 0.0 & 0.008 & 0.397 & 0.045 & 262 & ,805 \\
\hline & & YES & 50 & 0.309 & 0.222 & 0.187 & 0.000 & 0.010 & 1.000 & 0.154 & 0.133 & 0,832 \\
\hline & \multirow{4}{*}{$\min T_{\max }$} & $\mathrm{NO}$ & 15 & 1.000 & 0.840 & 0.334 & 0.000 & 0.003 & 0.067 & 0.433 & 0.007 & 0,740 \\
\hline & & $\mathrm{NO}$ & 50 & 0.648 & 0.847 & 0.704 & 0.000 & 0.001 & 0.046 & 1.000 & 0.011 & 0,806 \\
\hline & & YES & 15 & 0.365 & 0.384 & 0.055 & 0.000 & 0.000 & 0.011 & 0.537 & 0.001 & 1,000 \\
\hline & & YES & 50 & 0.104 & 0.343 & 0.156 & 0.000 & 0.001 & 0.013 & 0.277 & 0.003 & 1,000 \\
\hline & \multirow{4}{*}{$\min \overline{W I P}$} & $\mathrm{NO}$ & 15 & 1.000 & 0.632 & 0.235 & 0.104 & 0.000 & 0.256 & 0.267 & 0.107 & 0,534 \\
\hline & & $\mathrm{NO}$ & 50 & 0.613 & 0.823 & $\mid 0.791$ & 0.000 & 0.067 & 0.724 & 0.148 & 0.081 & 1,000 \\
\hline & & YES & 15 & 0.396 & 0.256 & 0.137 & 0.075 & 0.049 & 1.000 & 0.077 & 0.000 & 0,817 \\
\hline & & YES & 50 & 0.481 & 0.216 & $\mid 0.148$ & 0.090 & 0.091 & 0.208 & 0.315 & 0.000 & 1,000 \\
\hline & & \multicolumn{2}{|l|}{ var } & 0,117 & 0.072 & 0.056 & 0.002 & 0.001 & 0.130 & 0.078 & 0.008 & 0.021 \\
\hline & & \multicolumn{2}{|l|}{$\eta$} & 3,432 & 5.065 & 8.988 & 26.909 & 28.924 & 5.848 & 8.287 & 18.739 & 1.210 \\
\hline
\end{tabular}

Table 4. Robustness results for scenario A 
[Insert Figure 3 about here]

Figure 3. Signal-to-noise ratio for Scenario A

In this scenario DRs can be clearly divided in two groups. One group is formed by the DRs which reach the highest values of the signal-to-noise ratio (i.e. the most robust DRs): EDD, SI and FCFS rules, while the other group is formed by the rest of rules. The worst results are obtained by SRPT, SPT, performing similarly to SRO. LPT, CR and LS perform similarly. In general, it can be observed that those DRs based on the estimation some average times (SPT, SRPT, LPT, LS, CR) have a higher variance in the results as compared to those DRs independent of that estimations. In our opinion these it could be influenced by the variability on processing times (exponentially distributed) and the other source of variability in the shop as well.

\subsection{Scenario B (set-up times)}

Tables 5 to 7 (for every local performance measure) show the results for the distance, $d$. The NSUT rule is included in the study.

\begin{tabular}{|c|c|c|c|c|c|c|c|c|}
\hline \multirow{2}{*}{$\begin{array}{c}\text { Breakdowns } \\
\Delta t_{b}\end{array}$} & \multicolumn{4}{|c|}{ NO } & \multicolumn{4}{|c|}{ YES } \\
\hline & \multicolumn{2}{|c|}{$15 \%$} & \multicolumn{2}{|c|}{$30 \%$} & \multicolumn{2}{|c|}{$15 \%$} & \multicolumn{2}{|c|}{$30 \%$} \\
\hline \multirow{6}{*}{$z^{(1)}: 0 \leq d<25$} & FCFS & 0.0 & FCFS & 0.0 & NSUT & 0.0 & SI & 0.0 \\
\hline & NSUT & 13.1 & CR & 3.3 & LS & 6.7 & FCFS & 6.5 \\
\hline & CR & 16.0 & SI & 4.1 & SI & 12.9 & SRPT & 15.1 \\
\hline & SI & 19.7 & EDD & 10.1 & FCFS & 13.3 & EDD & 15.3 \\
\hline & & & SRPT & 23.2 & & & CR & 22.6 \\
\hline & & & SPT & 23.5 & & & NSUT & 23.3 \\
\hline \multirow{3}{*}{$z^{(2)}: 25<d \leq 50$} & EDD & 29.7 & NSUT & 25.5 & SRPT & 29.1 & SRO & 35.8 \\
\hline & & & LPT & 27.7 & SPT & 32.3 & & \\
\hline & & & SRO & 35.6 & EDD & 41.6 & & \\
\hline \multirow{3}{*}{$z^{(3)}: 50<d \leq 75$} & SRPT & 65.7 & & & CR & 62.2 & SPT & 56.2 \\
\hline & LPT & 71.1 & & & & & LPT & 60.0 \\
\hline & SPT & 72.9 & & & & & & \\
\hline \multirow[b]{2}{*}{$z^{(4)}: 75<d \leq 100$} & LS & 80.5 & LS & 100.0 & SRO & 98.9 & LS & 100.0 \\
\hline & SRO & 100.0 & & & LPT & 100.0 & & \\
\hline
\end{tabular}

Table 5. Results for scenario $\mathrm{B}, \min \bar{T}$ 
The inclusion of set-up times produces a strong increase of the variability in the system. For the first criterion studied, the DRs that are always contained in $z^{(1)}$ are SI and FCFS rules. It is also important to highlight the performance of the NSUT rule, obtaining results below $25.5 \%$. The NSUT performance deteriorates for accurate bottlenecks $\left(\Delta t_{b}=30 \%\right)$. The CR rule obtains good results for those scenarios without downtimes, and a poor performance for scenarios with downtimes. Time based rules obtained, in general, results far from the best positions. The SRPT rule obtains always better results than the SPT rule. Furthermore, increasing the variability in scenarios with set-ups produces worst results for the LS rule as compared with Scenario A. As a summary, the best results are reached for this criterion by the FCFS, NSUT, and SI rules.

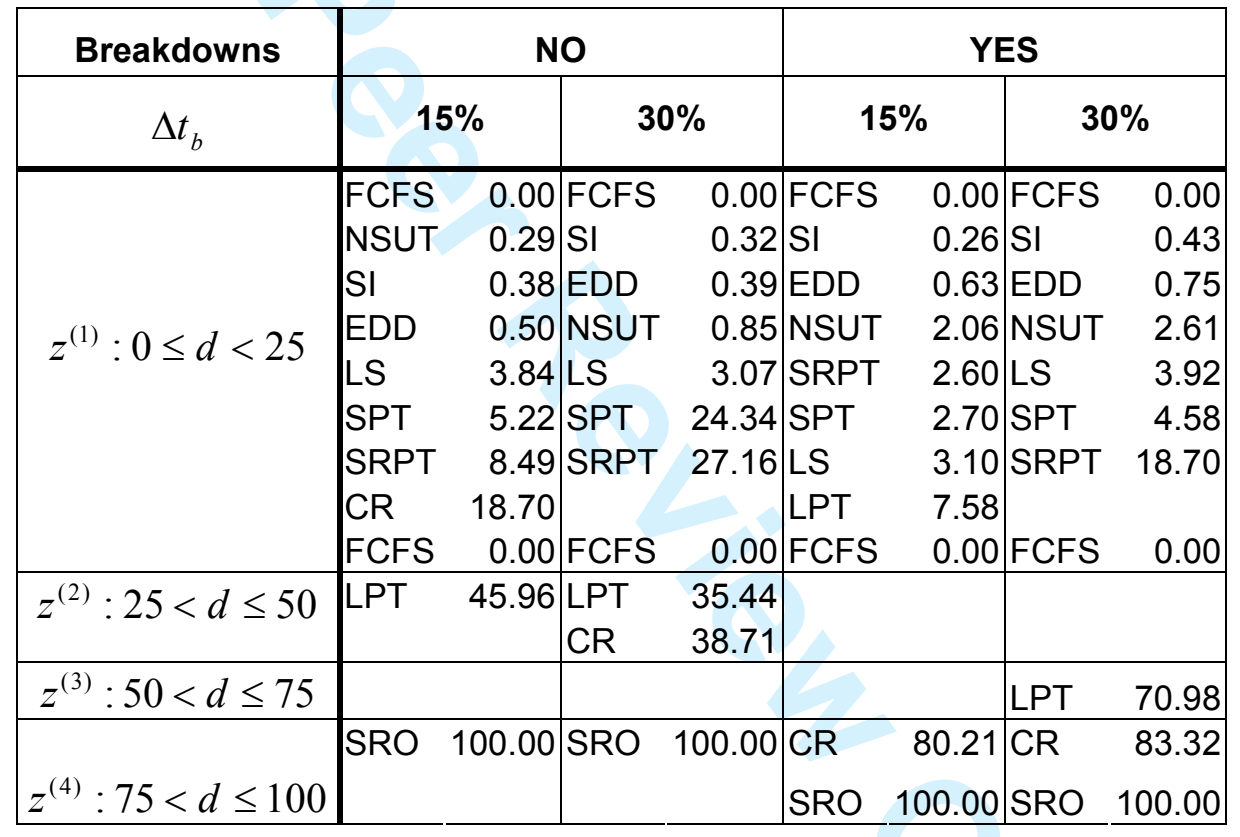

Table 6. Results for scenario $\mathrm{B}, \min T_{\max }$

For the minimisation of the maximum tardiness, the same effect than in Scenario A is observed, being FCFS, SI, and EDD the rules obtaining the best performance. As expected, the NSUT rule is also competitive. It is important to highlight that the use of DRs always obtain better results than a random selection. The CR rule obtains the worst results, compared to those obtained for the minimisation the average tardiness criterion. As a summary, best results are reached for this criterion by the FCFS, SI, NSUT, and EDD rules. 


\begin{tabular}{|c|c|c|c|c|c|c|c|c|}
\hline \multirow{2}{*}{$\begin{array}{c}\text { Breakdowns } \\
\Delta t_{b}\end{array}$} & \multicolumn{4}{|c|}{ NO } & \multicolumn{4}{|c|}{ YES } \\
\hline & \multicolumn{2}{|c|}{$15 \%$} & \multicolumn{2}{|c|}{$30 \%$} & \multicolumn{2}{|c|}{$15 \%$} & \multicolumn{2}{|c|}{$30 \%$} \\
\hline \multirow{9}{*}{$z^{(1)}: 0 \leq d<25$} & SI & 0.00 & SI & 0.00 & FCFS & 0.00 & FCFS & 0.00 \\
\hline & EDD & 0.06 & FCFS & 0.23 & SI & 0.13 & $\mathrm{SI}$ & 6.23 \\
\hline & FCFS & 0.13 & EDD & 0.27 & EDD & 0.16 & EDD & 9.91 \\
\hline & NSUT & 0.95 & NSUT & 0.97 & NSUT & 3.98 & SRPT & 19.34 \\
\hline & SRPT & 12.55 & SRPT & 8.06 & SPT & 18.03 & 3 NSUT & 20.29 \\
\hline & & & SPT & 16.12 & & & LPT & 20.51 \\
\hline & & & SRO & 20.91 & & & & \\
\hline & & & CR & 24.48 & & & & \\
\hline & SI & 0.00 & SI & 0.00 & FCFS & 0.00 & FCFS & 0.00 \\
\hline \multirow{3}{*}{$z^{(2)}: 25<d \leq 50$} & SPT & 29.44 & & & SRPT & 27.16 & $\mathrm{CR}$ & 26.12 \\
\hline & CR & 30.89 & & & SRO & 29.11 & & \\
\hline & SRO & 47.61 & & & LS & 41.65 & & \\
\hline \multirow{2}{*}{$z^{(3)}: 50<d \leq 75$} & LPT & 68.79 & LPT & 69.40 & CR & 59.73 & SPT & 53.40 \\
\hline & & & & & & & LS & 88.33 \\
\hline$z^{(4)}: 75<d \leq 100$ & LS & 100.00 & LS & 100.00 & LPT & 100.00 & SRO & 100.00 \\
\hline
\end{tabular}

Table 7. Results for scenario $\mathrm{B}, \min \overline{W I P}$

Under the criterion of minimising the average work in process, the same behaviour than in Scenario A is obtained, but now including the NSUT rule. It is also important to mention that the SRPT rule obtains always results lower than $27.16 \%$. Results obtained by the SPT are moderate. The LS rule seems to be not competitive under the studied conditions. As a summary, best results are reached for this criterion by the SI, FCFS, ESS, and NSUT rules.

Regarding the robustness global criteria, results are summarized in Table 8 and in Figure 4.

\begin{tabular}{|c|c|c|c|c|c|c|c|c|c|c|c|c|c|}
\hline & Criteria & Breakdows & $\Delta t_{b}$ & SPT & SRPT & LPT & SI & EDD & LS & CR & FCFS & SRO & NSUT \\
\hline \multirow{12}{*}{ 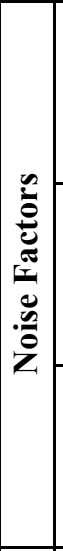 } & \multirow{4}{*}{$\min \bar{T}$} & NO & 15 & 0.729 & 0.657 & 0.711 & 0.197 & 0.297 & 0.805 & 0.160 & 0.000 & 1.000 & 0.131 \\
\hline & & NO & 50 & 0.235 & 0.232 & 0.277 & 0.041 & 0.101 & 1.000 & 0.033 & 0.000 & 0.356 & 0.255 \\
\hline & & YES & 15 & 0.323 & 0.291 & 1.000 & 0.129 & 0.416 & 0.067 & 0.622 & 0.133 & 0.989 & 0.000 \\
\hline & & YES & 50 & 0.562 & 0.151 & 0.600 & 0.000 & 0.153 & 1.000 & 0.226 & 0.065 & 0.358 & 0.233 \\
\hline & \multirow{4}{*}{$\min T_{\max }$} & $\mathrm{NO}$ & 15 & 0.052 & 0.085 & 0.460 & 0.004 & 0.005 & 0.038 & 0.187 & 0.000 & 1.000 & 0.003 \\
\hline & & $\mathrm{NO}$ & 50 & 0.243 & 0.272 & 0.354 & 0.003 & 0.004 & 0.031 & 0.387 & 0.000 & 1.000 & 0.009 \\
\hline & & YES & 15 & 0.027 & 0.026 & 0.076 & 0.003 & 0.006 & 0.031 & 0.802 & 0.000 & 1.000 & 0.021 \\
\hline & & YES & 50 & 0.046 & 0.187 & 0.710 & 0.004 & 0.007 & 0.039 & 0.833 & 0.000 & 1.000 & 0.026 \\
\hline & \multirow{4}{*}{$\min \overline{W I P}$} & $\mathrm{NO}$ & 15 & 0.294 & 0.125 & 0.688 & 0.000 & 0.001 & 1.000 & 0.309 & 0.001 & 0.476 & 0.010 \\
\hline & & $\mathrm{NO}$ & 50 & 0.161 & 0.081 & 0.694 & 0.000 & 0.003 & 1.000 & 0.245 & 0.002 & 0.209 & 0.010 \\
\hline & & YES & 15 & 0.180 & 0.272 & 1.000 & 0.001 & 0.002 & 0.416 & 0.597 & 0.000 & 0.291 & 0.040 \\
\hline & & YES & 50 & 0.534 & 0.193 & 0.205 & 0.062 & 0.099 & 0.883 & 0.261 & 0.000 & 1.000 & 0.203 \\
\hline & & \multicolumn{2}{|l|}{ var } & 0.050 & 0.027 & 0.087 & 0.004 & 0.019 & 0.208 & 0.069 & \begin{tabular}{|l|}
0.002 \\
\end{tabular} & 0.119 & 0.010 \\
\hline & & \multicolumn{2}{|l|}{$\eta$} & 9.027 & \begin{tabular}{|l|}
11.537 \\
\end{tabular} & 3.992 & 22.941 & 15.950 & 3.301 & 6.697 & 27.401 & 1.990 & 18.224 \\
\hline
\end{tabular}

Table 8. Robustness results for scenario B 
[Insert Figure 4 about here]

Figure 4. Signal-to-noise ratio for Scenario B

In this case, the gain (signal-to-noise ratio) is decreasing linearly from the best to the worst DR. The highest values of the signal-to-noise ratio (i.e. the most robust DRs) are obtained by FCFS, SI, NSUT and EDD, and the worst by LPT, LST, performing similarly to SRO. The results in this scenario show that the use of FCFS, SI, NSUT and EDD rules has important advantages with respect to not considering any rule (SRO). Regarding to variability, the same behaviour than Scenario A was found. According to the results, we recommend the use of FCFS or SI under set-up conditions, and EDD or SI if there is not set-up.

From a managerial point of view, it is important to remark that each DR implies a different sophistication level regarding its implementation. For example, the FIFO rule can be implemented easily either by exploiting the conveyors layout or visually in human manipulations. However, more sophisticated DR (e.g. EDD, or CR) require the support of an information system or a MES (Manufacturing Execution System) in order to be implemented. However, it is important to consider that for some local performance measures $\left(\min T_{\max }\right.$, and $\left.\min \overline{W I P}\right)$ the FIFO rules obtain the best or similar results than EDD for those scenarios including set-up times and machine breakdowns (see Tables 2 and 3). Furthermore, in Table 4 it can be observed that the second and third robust DRs correspond to the SI and FIFO rules, which need less sophisticated controlling mechanisms in order to be implemented.

\section{Conclusions}

In this work it has been shown that DRs are dependent of the production nature (job-shop, flow-shop, assembly, etc,...) as well as of the stochastic variability conditions, produced by processing times, breakdowns, set-ups, etc... In order to correctly select a DR, two possible approaches can be distinguished:

(1) introducing a dynamic procedure in order to switch in real-time to the most profitable DR, or (2) selecting a robust DR which can stand different environmental changes. TOC and particularly DBR 
advocate for simple procedures, avoiding complex procedures like (1). Thus, the selection of robust DRs can be a good option to be used in practise for DBR systems. Furthermore, this approach is related to nowadays market performance, since in the global era the markets are characterized for a more volatile demand, where from the design processes of new products, the production processes and later distribution to customers have to be adapted to its requirements. From a production point of view, these changes can produce a stressing behaviour in manufacturing, and therefore, mechanisms and policies trying to absorb these changes are welcome. In this sense, the proposed methodology can be used in order to provide the DBR production with the most profitable dispatching rules for a given scenario.

As stated previously, DRs are sensitive to the production environment under study. In order to correctly explain the proposed methodology for robust DR selection under DBR systems we focus on a simple, but widely common in practise, flow-line system. In our approach, we study different scenarios, including different relative utilization of the bottleneck, machine breakdowns, and set-up times. Local performance measures were computed and discussed for each scenario and every DR. Finally, the global performance of every DR is evaluated using Taguchi's robustness concept. Results shown that the most robust DRs are the EDD, SI and FCFS for environments without set-ups; and FCFS and SI for the case of set-ups. It is also worth noting that, for scenarios with set-up times, NSUT could be also a good alternative. Another interesting result is that some rules perform worst that the SRO rule. These results are consistent to the work of Chang et al. (1996), who observed the same phenomenon for different performance measures. The results are also consistent with those of Fry et al. (1992), who point out that the dispatching rules used in the OPT software were based on a trade of customer due-dates avoiding bottleneck set-ups times.

In our analysis we have consider only ten dispatching rules. Future research could extend the study to additional dispatching rules. Additionally, it could be interesting to extend the study to the effect of changes in the product mix, trying to identify those rules most robust under product mix variability conditions. Chakravorty and Atwater (2005) point out that DBR is very sensitive regarding the availability 
of raw material in front of the shop. This aspect could be included in a future research. Finally, it seems interesting address a hybrid combination of a global scheduling system and dispatching rules, such as pointed out by Roundy et al. (1991). Dynamic DRs selection in real-time by means of human-computer interactive systems for DBR can also be of interest (see e.g. Baek et al. 1999, or Kuo and Hwang, 1999).

\section{Appendix: Definition of the dispatching rules}

Despite the voluminous literature on the topic, there are no homogeneous definitions for some dispatching rules. Sometimes the same rule has different acronyms, or one acronym has different meanings. Therefore, in order to unambiguously describe the dispatching rules employed in our study, we briefly define them and indicate the reference from which each definition has been obtained. In order obtain practical results it was assumed that real processing times of job are unknown in advance. The following notation is used:

$Z_{i j}$, the priority of job $i$ in station $j$ at time $t$. Small values have greatest priority. $Z_{i b}$ refers for the priority of job $i$ in bottleneck station.

$t$, the current time.

$t_{i j}$, the mean processing time of job $i$ in machine $j . t_{i b}$ refers to the processing time at bottleneck station.

$C T_{i}(t)$, the average cycle time of job $i$ at time $t$.

$n$, the number of stations in the line.

$D D_{i}$, the due-date of job $i$.

$A T_{i, j}$, the arrival time of job $i$ at the queue of the station $j$.

The rules under comparison are the following:

a) Processing time based: 
- SPT, Shortest Processing Time (Montarezi and Van Wassenhove, 1990). Select the job with the shortest processing time, i.e., selects the minimum $Z_{i b}$, where: $Z_{i b}=C T_{i}$.

- SRPT, Shortest Remaining Processing Time (Wu et al. 2008). Select the job with the shortest remaining processing time, i.e., selects the minimum $Z_{i b}$, where: $Z_{i b}=C T_{i}-\left(t-A_{i 1}\right)+\sum_{j=b}^{n} t_{i j}$.

- LPT, Longest Processing Time (Montarezi and Van Wassenhove, 1990). Select the job with the longest processing time, i.e., select the minimum $Z_{i b}$, where: $Z_{i b}=-C T_{i}$.

b) Due-date based:

- EDD, Earliest Due Date (Panwalkar and Iskander, 1977). Select the job with the earliest due-date, that is, select the minimum $Z_{i b}$, where: $Z_{i b}=D D_{i}$.

- CR, Critical Ratio (Seagle and Fisk, 1982). Select the job with the minimum ratio, computed as the remaining time to the due-date divided by the remaining processing time, that is, select the minimum $Z_{i b}$, where: $Z_{i b}(t)=\left(D D_{i}-t\right) /\left(t-A_{i 1}\right)$.

- SI Truncated (see e.g. Blackstone et al., 1982 and Pierreval and Mebarki, 1997). A modified version of the $\mathrm{SI}^{\mathrm{X}}$ was implemented because obtained better results. Two queues are formed. Randomly some $\alpha \%$ of jobs go to first queue, while the rest go to the queue ordered by the due date.

- LS, Least Slack (Pierreval and Mebarki, 1997). Select the job the minimum slack time, that is, select the minimum $Z_{i b}$, where: $Z_{i b}=D D_{i}-C T_{i}-A_{i 1}$.

c) Set-up time based:

- NSUT, No Set-Up Time (Panwalkar and Iskander, 1977). Select the job that requires no set-up time.

d) Arrival Times and Random based:

- FCFS, First Come First Served (Panwalkar and Iskander, 1977). Jobs are selected according to the arrival time. The priority is computed selecting the minimum $Z_{i b}$, where: $Z_{i b}=A T_{i b}$. 
- SRO, Select in Random Order (Panwalkar and Iskander, 1977). Job is randomly selected. The priority is computed selecting $Z_{i b}$, where: $Z_{i b}=$ Random .

Usually it is possible that priority of different jobs reach the same value. These tie situations are usually solved by the FCFS rule, which was also followed in this work.

\section{Acknowledgements}

The authors wish to thank the anonymous referees for their helpful suggestions. This research has been supported by the Spanish National Research Plan under DPI2007-61345 project and by the Andalusian Government Research Plan under P08-TEP-3630 project.

\section{References}

Aytug, H., Lawley, M.A., McKay, K., Mohan. S. and Uzsoy, R., 2005, Executing production schedules in the face of uncertainties: a review and some future directions. European Journal of Operational Research, 161, 86-110.

Baek, D.H., Oh, S.Y., Yoon, W.C., 1999. A visualized human-computer interactive approach to job shop scheduling. International Journal of Computer Integrated Manufacturing, 12(1), 75-83.

Baker, K. R., 1984, The effects of input control in a simple Scheduling model. Journal of Operations Management, 4(1), 99-112.

Blackstone Jr., J. H., Phillips, D. T. and Hogg, G. L., 1982, A state-of-the-art survey of dispatching rules for manufacturing job shop operations. International Journal of Production Research, 20(1), 27-45.

Blackstone Jr., J. H., Cox III, J.F., 2002, Designing unbalanced lines - understanding protective capacity and protective inventory. Production Planning \& Control, 13(4), 416-424. 
Bonvik, A.M., Couch, C.E. and Gershwin, S.B., 1997, A comparison of production-line control mechanisms, International Journal of Production Research, 25(3), 789-804.

Chakravorty, S.S., 2001, An evaluation of the DBR control mechanism in a job shop environment. Omega. The International Journal of Management Science, 29, 335-342.

Chakravorty S. S., Brian J., 2005, The impact of free goods on the performance of drum-buffer-rope scheduling systems. International Journal of Production Economics, 95(3), 347-357.

Chang, T.M. and Yih, Y., 1994, Determining the number of kanbans and lot sizes in a generic kanban system: a simulated annealing approach. International Journal of Production Research, 32(8), 1991-2004.

Chang, Y.L., Sueyoshi, T. and Sullivan, R. S., 1996, Ranking dispatching rules by data envelopment analysis in a job shop environment. IIE Transactions, 28, 631-642.

Corbett, T., Csillag, J.M., 2001, Analysis of the effects of seven drum-buffer-rope implementations. Production and Inventory Management Journal, 42(3/4), 17-24.

Daniel, V. and Guide Jr., R., 1997, Scheduling with priority dispatching rules y drum-buffer-rope in a recoverable manufacturing system. International Journal of Production Economics, 53, 101-116.

Duenyas, I., 1994, A simple release policy for network of queues with controllable inputs. Operations Research, 42, 1162-1171.

Erenguc, SS, Tirupati, D., and Woodruff, D., 1997, Introduction to the Special Issue on Capacity Constrained Planning and Scheduling. Production and Operations Management, 6(1),1-2. 
Framinan, J.M., Ruiz-Usano, R. and Leisten, R., 2000, Input Control and dispatching rules in a dynamic CONWIP flow-shop. International Journal of Production Research, 39(18), 4589-4598.

Fry, T. D., Blackstone, J.H. and Cox, J.F., 1992, An analysis and discussion of the optimized production technology software and its use. Production and Operations Management Journal, 1(2), 229-242.

Goldratt, E.M. and Cox, J., 1984, The Goal: An Ongoing Improvement Process (North River Press, NY).

Goldratt, E.M. and Fox, J., 1986, The Race (North River Press, NY).

Goldratt, E., 1990, The Haystack Syndrome, sifting information in the data ocean (North River Press, NY.).

Guide, V. D. R., 1996, Scheduling using drum-buffer-rope in a remanufacturing environment. International Journal of Production Research, 34(4), 1081-1091.

Gilland, W., 2002, A simulation study comparing performance of Conwip and bottleneck-based release rules. Production Planning \& Control, 13(2), 211-219.

Hopp, W.J. and Roof, M.L., Setting WIP levels with statistical throughput control (STC) in CONWIP production lines, International Journal of Production Research, 36(4), 867-882.

Kayton, D., Teyner, T., Schwartz, C., Uzsoy, R., 1996, Effects of dispatching and down time on the performance of wafer fabs operating under theory of constraints. Electronics Manufacturing Technology Symposium, 1996., Nineteenth IEEE/CPMT, (14)16,49-56. 
Kayton, D., Teyner, T., Schwartz, C., Uzsoy, R., 1996, Focussing maintenance improvement efforts in a wafer fabrication facility operating under the theory of constraints. Production and Inventory Management Journal, (38)4, 51-57.

Kempf, K., 1998, Improving throughput across the factory life-cycle. Intel Technology Journal Q4'98.

Koh, S. -G., Bulfin, R.L., 2004, Comparison of DBR with CONWIP in an unbalanced production line with three stations. International Journal of Production Research, 42(2), 391-405.

Kodipasaoglu, S. N., Xiang, W., Hurley, S. F. and Khumawala, B. M., 2000, A study on the effect of the extent and location of protective capacity in flow systems. International Journal of Production Economics, $63,217-228$

Kuo, W-H. and Hwang, S-L., 1999. The development of a human-computer interactive scheduling system. International Journal of Computer Integrated Manufacturing, 12(2), 156-167.

Lambrecht, M. and Segaert, A., 1990, Buffer stock allocation and assembly type production lines. International Journal of Operations \& Production Management, 10(2), 47-61.

Lalas,C., Mourtzis, D., Papakostas, N. and Chryssolouris, G., 2006, A simulation-based hybrid backwards scheduling framework for manufacturing systems. International Journal of Computer Integrated Manufacturing, 19(8), 762-774.

Law, A. M. and Kelton, W. D., 1991, Simulation Modeling and Analysis, 2nd edition (McGraw-Hill: New York). 
Lawrence, S.R. and Sewell, S.E., 1997, Heuristic, optimal, static and dynamic schedules when processing times are uncertain. Journal of Operations Management, 15, 71-82.

Lee, Y.F., Jiang, Z.B. and Liu H.R., 2009. Multiple-Objective scheduling and real-time dispatching for the semiconductor manufacturing system. Computers \& Operations Research, 36, 866-884.

Lixing, W., Hock, F. T. E. and Hay, L.L., 2000, Scheduling MEMS Manufacturing. Proceeding of the 2000 Winter Simulation Conference.

Mabin, V. and Balderstone, S., 2000, The World of the Theory Of Constraints: A Review of the International Literature (Sant Lucie Press/APICS Series of Constraints Management).

Moeeni, F., Sanchez, S.M. and Vakharia, A.J., 1997, A robust design methodology for Kanban system design. International Journal of Production Research, 35, 2821-2838.

Monden, Y., 1983, Toyota production system (Industrial Engineering and Management Press, Atlanta).

Montarezi, M. and Van Wassenhove, N., 1990, Analysis of scheduling rules for an FMS. International Journal of Production Research, 28(4), 785-802.

Mouelhi-Chibani, W. and Pierreval, H., 2009, Training a Neural Network to select dispatching rules in real time. Computers \& Industrial Engineering, doi: 10.1016/j.cie.2009.03.008.

Panwalkar, S. S. and Iskander, W., 1977, A survey of scheduling rules. Operations Research, 25(1), 45-61. 
Pierreval, H. and Mebarki, N., 1997, Dynamic selection of dispatching rules for manufacturing system scheduling. International Journal of Production Research, 35(6), 1575-1591.

Ramsay, M.L., Brown, S. and Tabibzadeh, K., 1990, Push, pull and squeeze shop floor control with computer simulation. Industrial Engineering, 22(2), 39-45.

Ramesh, R., 1990, Dynamic job shop scheduling: a survey of simulation research. Omega, 18,43-57.

Riezebos, J., Korte, G.J., Land, M.J., 2003, Improving a practical DBR buffering approach using Workload Control. International Journal of Production Research, 41(4), 699-713.

Roundy, R.O., Maxwell, W.L., Herer, Y.T., Tayur, S.R., Getzler, A.W., 1991, A price directed approach to real-time scheduling of production operations. IIE Transactions 23, 149-160.

Russell, G. R. and Fry, T. D., 1997, Order review/release and lot splitting in drum-buffer-rope. International Journal of Production Research, 35(3), 827-845.

Schragenheim, E. and Ronen, B., 1990, Drum-buffer-rope shop floor control. Production and Inventory Management, 31(3), 18-22.

Schragenheim, E. and Ronen, B., 1991, Buffer management: a diagnostic tool for production control. Production and Inventory Management, 2nd Quarter, 32(1), 74-79.

Seagle, J. P., and Fisk, J.C., 1982, Application of work center control rules in a job shop environment. Journal of Operations Management, 3(1), 43-48. 
Simons, J. V., Stephens, M. D. and Simpson, W. P., 1999, Simultaneous versus sequential scheduling of multiple resources which constrain system throughput. International of Production Research, 37(1), 21-33.

Sivassubramanian, R., Selladurai, V. and Rajamramusamy, N., 2000, The effect of the drum-buffer-rope (DBR) approach on the performance of a synchronous manufacturing systems (SMS). Production Planning \& Control, 11(8), 820-824.

Spearman, M. L., Woodruff, D.L. and Hoop, W.J., 1990, Conwip: a pull alternative to Kanban. International Journal of Production Research, 28(5), 879-894.

Spencer, M. S. and Cox, J. F., 1995, Optimum production technology (OPT) and the theory of constraints (TOC): analysis and genealogy. International Journal of Production Research, 33, 1495-1504.

Taguchi, G., 1986, Introduction to quality engineering: designing quality into products and processes. (White Plains, New York: Kraus International Publications).

Taguchi, G. and Wu, Y., 1980, Introduction to Off-line Quality Control. (Central Japan Quality Control Association, available from American Supplier Institute, Detroit).

Umble, M. and Srikanth, M.L., 1990, Synchronous Manufacturing: Principles for World Class Excellence (South-Western Publishing, OH).

Ye, T. and Han, W., 2008. Determination of buffer sizes for drum-buffer-rope (DBR)-controlled production systems. International Journal of Production Research, 46(10), 2827-2844.

Wu, M-C., Jiang, J-H. and Chang, W-J., 2008, Scheduling a hybrid MTO/MTS semiconductor fab with machine-dedication features. International Journal of Production Economics, 112, 416-426. 


\section{FIGURES}

\section{List of Figure captions}

Figure 1. WIP-buffer DBR implementation

Figure 2. WIP-buffer DBR implementation for three type of products

Figure 3. Signal-to-noise ratio for Scenario A

Figure 4. Signal-to-noise ratio for Scenario B 
FIGURES

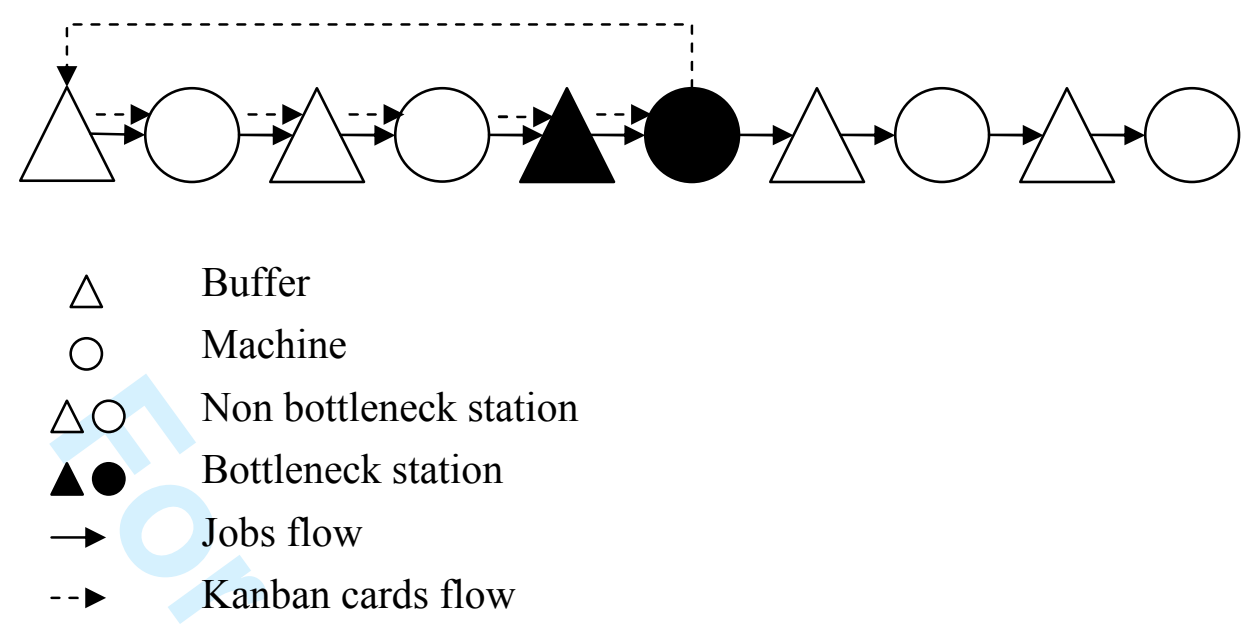

Figure 1. WIP-buffer DBR implementation

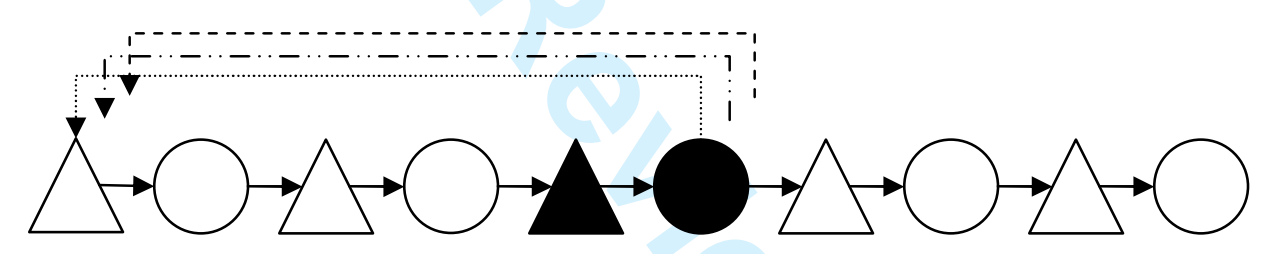

$\triangle \bigcirc \quad$ Non bottleneck station

$\Delta$ Shared Bottleneck station

$\rightarrow$ Jobs flow

$\rightarrow \quad$ Kanban cards flow, job type I

$\rightarrow \quad$ Kanban cards flow, job type II

$\rightarrow \quad$ Kanban cards flow, job type III

Figure 2. WIP-buffer DBR implementation for three type of products 
FIGURES

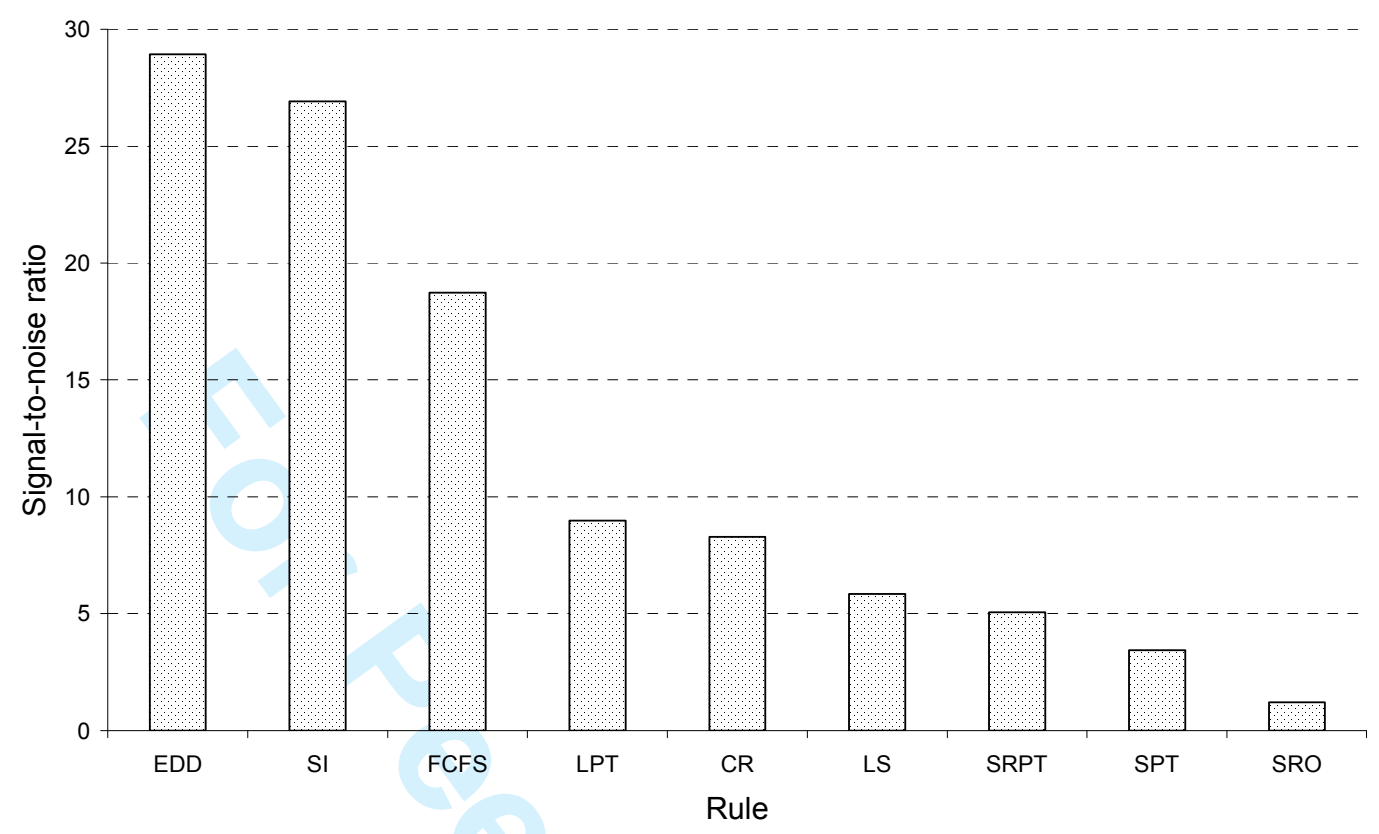

Figure 3. Signal-to-noise ratio for Scenario A

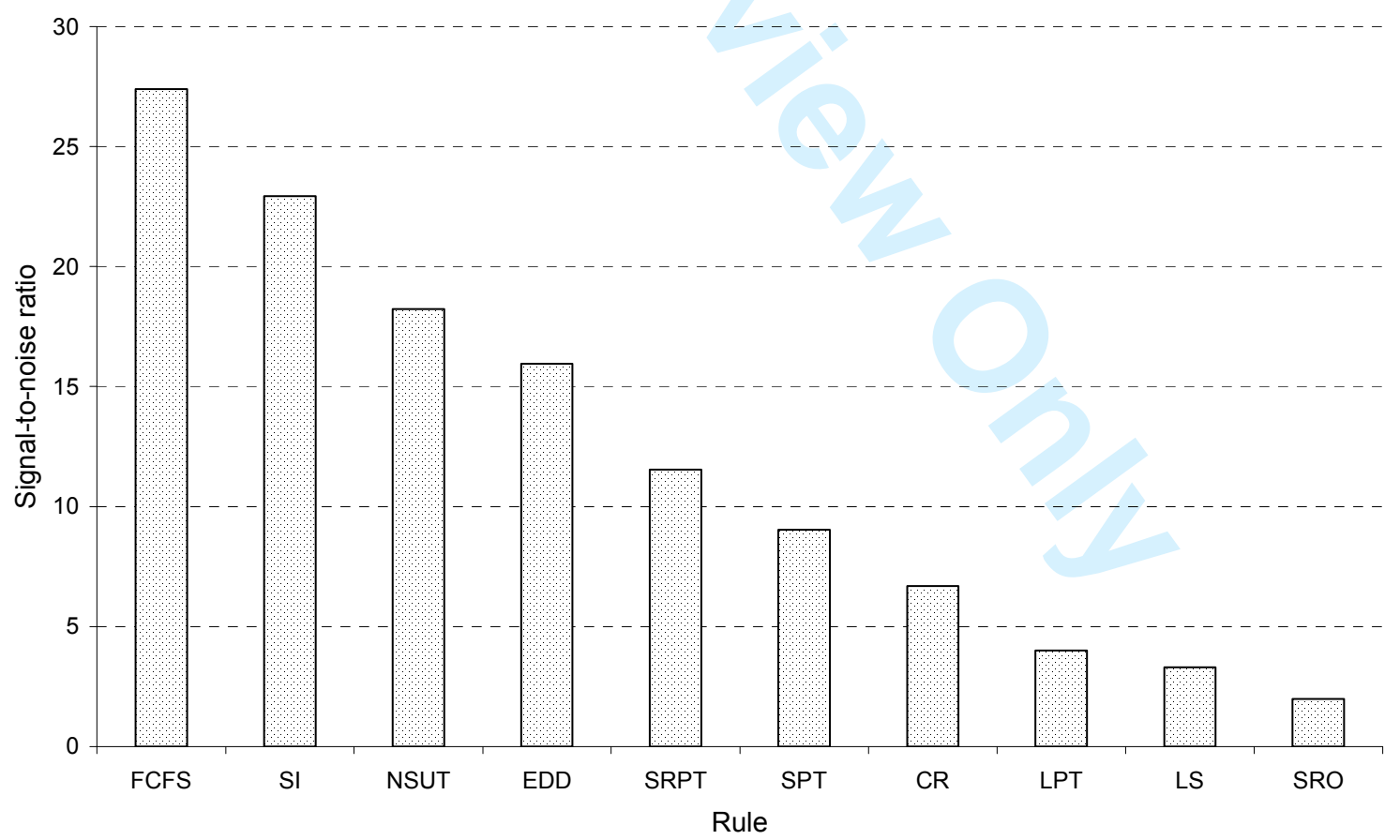

Figure 4. Signal-to-noise ratio for Scenario B 